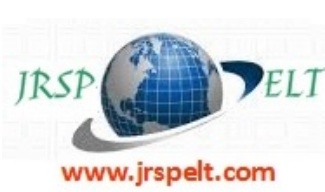

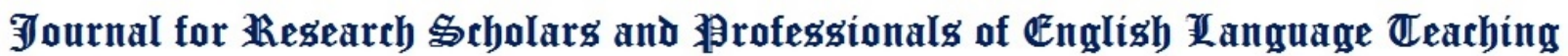

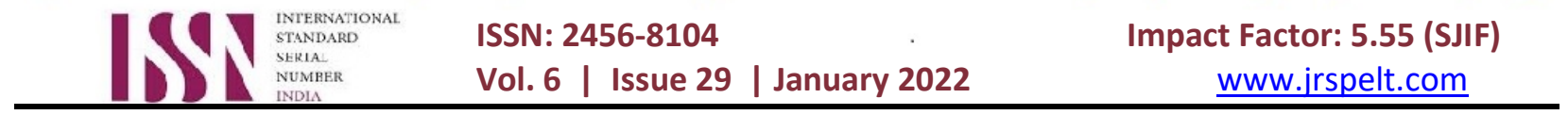

\section{The Academic Language Used in Scientific Research}

Dr. V. Chandra Sekhar Rao (csrao46@gmail.com)

Professor Emeritus in English, Hyderabad, India, ORCID: 0000-0002-3584-1438

\section{(c) (i) 8)}

Copyright: (C) $\mathbf{2 0 2 2}$ by the authors. Licensee JRSP-ELT (2456-8104). This article is an open access article distributed under the terms and conditions of the Creative Commons Attribution Non-Commercial 4.0 International License. (https://creativecommons.org/licenses/ by-nc/4.0/)

DOI: https://doi.org/10.54850/jrspelt.6.29.03
Abstract: Academic language is substantially more formal, nuanced, and sophisticated than informal spoken language used outside of the classroom. Academic language takes centre stage in curriculum development and implementation. Academic language is the language required by students to appreciate and communicate in the academic setting; and it follows a set of principles that are precise, formal, and scientific, as well as objective and analytical in nature. Academic language is more concerned with terminology, norms and genres. The instruction and learning of academic language entails more than just studying a range of linguistic features. English has been used to produce scientific papers that discuss tense choice, clarity, preciseness, style, assortment of sentence, diction, and other features of language utilised in scientific writing.

Keywords: Academic language, Grammar and Terminology, Linguistic Features, Scientific Language, Scientific Research

\section{Introduction}

The term "academic language" refers to the language used in academic settings. It is substantially more formal, nuanced, and sophisticated than informal spoken language used outside of the classroom. Each subject has its own terminology and linguistic function. Academic language also includes syntax, discourse, and other basic academic jargon that extends in all fields. To comprehend the meanings of words and how they are employed in diverse situations and subjects, students must have a good understanding of basic academic language.

Language is the essential resource or tool with which teachers and pupils collaborate in classrooms (Frances Christie, 2005). It should be noted that language education has struggled for decades with defining academic language and positioning it within an assets-based approach to assure the academic success of culturally and linguistically assorted pupils. Academic language takes centre stage in curriculum development and implementation, affecting every instructor on a daily basis. The practice of academic language and its use in education is highly prevalent. It is an entail to understand academic language's responsibilities, aspects, and underlying ideas, as well as the developmental nature of language learning.

\section{Definitions of Academic Language}

It is universally agreed that academic language is indeed comprehensive and content-specific. It means, numerous academic terms belonging to certain topic areas are utilised in all educational contexts. It's crucial to keep in mind that academic language encompasses more than just subject terminology relating to specific disciplines. Academic language, on the other hand, refers to the complete range of language used in academic settings; here are some definitions for students' awareness:

"Academic language is the language needed by students to understand and communicate in the academic disciplines. Academic language includes such things as specialized vocabulary, conventional text structures within a field (e.g., essays, lab reports) and other language-related activities typical of 


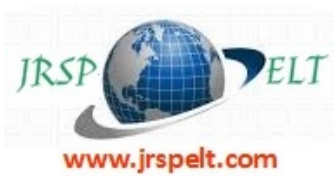

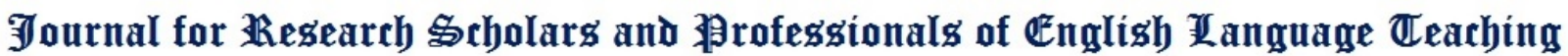

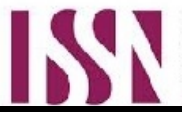

INTERRATIONA

classrooms, (e.g., expressing disagreement, discussing an issue, asking for clarification). Academic language includes both productive and receptive modalities", (Conference of Performance Assessment for California Teachers-PACT).

Academic language is "the language that is used by teachers and students for the purpose of acquiring new knowledge and skills ... imparting new information, describing abstract ideas, and developing students' conceptual understandings" (Chamot \& O'Malley, 1994, p. 40).

Academic language refers to "word knowledge that makes it possible for students to engage with, produce, and talk about texts that are valued in school" (Flynt \& Brozo, 2008, p. 500).

"Academic language is the set of words, grammar, and organizational strategies used to describe complex ideas, higher-order thinking processes, and abstract concepts", (Zwiers, 2008, p. 20).

Rao, C S (2018) says that academic English is intended for reading and comprehending study materials as well as writing about them. For the reader's understanding, writing for academic or scientific study should be lucid, succinct, exact, and accurate in meaning.

Language is likely the most powerful tool available to instructors, aside from the definitions provided, because it is prevalent in every element of the teaching and learning process. Language is always a source of meaning creation and communication.

Academic language encompasses more than only vocabulary and grammar in reading, writing, listening, and speaking, despite the lack of a precise definition. Learning academic English can be difficult, especially for non-native speakers, due to the abundance of grammatical quirks, symbols, idiomatic expressions, and slang in the English language. Academic language necessitates students' mastery of several linguistic systems or contextual language apart from syntactic norms.

\section{Academic Language and Its Nature}

Academic language follows a set of principles that are precise, formal, and scientific, as well as objective and analytical in nature. Learners usually believe that academic language is complicated to write and comprehend. Academic subject areas are difficult to learn because they are connected to academic specialized varieties of language and some other particular symbol systems which are sophisticated, technical, and primarily alienating to several learners (Gee, 2004).

Academic language has been at the focus of many educational activities in recent years, but educators and academics have conceptualized academic language in a variety of ways. Numerous researchers have identified teachers' comprehension of academic language as a difficult content-area, terminology, or "difficult words" in the classroom. Academic language, on the other hand, is a complicated idea to grasp. Changes in language use in terms of word selection, formality, sentence structures, and speaking style arise from differences in objective, audience, and situation.

In broad terms, academic language alludes to the language used in education to acquire new or better knowledge of topics and to communicate that information to others. Academic language enables students to think and act like scientists, historians, and mathematicians as it conveys the abstract, technical, and sophisticated concepts and phenomena of the subjects. As a result, academic language encourages and facilitates a distinct type of thinking than everyday language.

Literally students need to know and be able to use specific linguistic elements associated with academic disciplines in order to access disciplinary information and materials and to partake effectively in activities and evaluations. Conversational aspects, grammatical structures, and terminology are among the attributes found across diverse language domains and topic areas. Academic language also serves other purposes, like displaying sophistication, higher-order thinking, and conceptualization. 


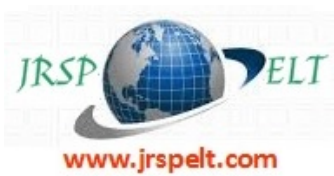

\section{Journal for Research Gébolars and 羽rofessionals of Énglish Yanguage Teaching}

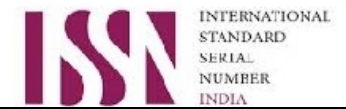

ISSN: 2456-8104

Vol. 6 | Issue 29 | January 2022

Impact Factor: 5.55 (SJIF)

www.jrspelt.com

\section{Spoken and Written Forms}

Generally people notice that the distinctions between spoken and written languages. In most circumstances, the language used in nonfiction writing will be considerably different from that used by two friends speaking in a hotel. There may be some similarities between spoken and written language on rare instances, such as during a class lecture, a legal consultation, a post-collision talk with a law enforcement officer, or in a text message. Texting, tweeting, and other types of short messaging services (SMS) typically communicated by mobile phone networks are illustrations of variations between spoken and written forms.

There are significant distinctions between how we speak and how we write in general. Due to additional indications such as body language, voice, volume, and resonance, spoken language can be more communicative than written language. Spoken language is frequently based on face-to-face interaction. Except for formal speeches or written presentations, spoken language is full of loops, imperfect sentences, errors, and pauses.

Written language, on the other hand, is more formal than spoken language. Oral language is less precise than written language. Written language can be more sophisticated and complicated than spoken language. Written language maintains particular organisational, expressiveness, and logical characteristics. In most cases, written language is unchangeable; and punctuation, headings, design, colours, and other graphical elements are used in written language, but not available in oral language.

\section{Academic Language Awareness}

Academic language is more concerned with terminology, norms and genres. The instruction and learning of academic language entails more than just studying a range of linguistic features. It includes information about means of being in the universe, ways of performing, understanding, communicating, evaluating, believing, presenting, and occasionally writing and reading, all of which are associated with specific identities and social tasks; to put it differently, language must be comprehended in accordance with the speakers, the goal of the communication, the target audience and the environment in which it is used.

Language does not exist in a vacuum; it is embedded in a societal framework. The sociocultural milieu for acquiring academic language is frequently the classroom environment. Although the students' diverse origins, experiences and perspectives have to be taken into account, the classroom serves as a conduit for the accumulation of individual learning that develops to commonality.

There are instructors and learners becoming increasingly aware of the numerous procedures associated with language acquisition. Students are more and more aware of how they acquire, and teachers are now more sensitive in how they educate, in addition to the sociocultural factor that pervades the classroom.

Teacher language awareness is more popular among those equipping educators to work with linguistically and culturally diverse children. Nevertheless, since globalisation has made classrooms exceedingly diverse over the last several decades, all instructors, irrespective of subject area or grade-level competence, have become de facto educators.

\section{Academic Language and Science}

Lemke began studying science discourse and its consequences for pupils learning English as a second language during 1980s. At that moment, he viewed educators had come to recognise that mastery of academic subjects entails mastery of their specific patterns of language usage, and that language is the main medium through which these subjects are instructed and students' mastery of them assessed.

According to Lemke (1990), "scientific language has a preference in its grammar for using the passive voice ... people tend to disappear from science as actors or agents . . . and there is a grammatical 


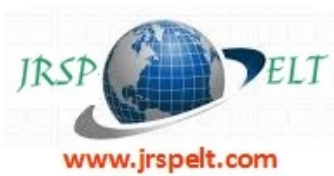

\section{Journal for Research Gébolars and 羽rofessionals of Énglish Yanguage Teaching}

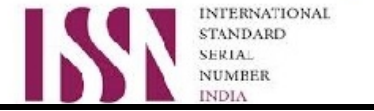

ISSN: 2456-8104

Vol. 6 | Issue 29 | January 2022
Impact Factor: 5.55 (SJIF)

www.jrspelt.com

preference for using abstract nouns derived from verbs". He claims that these stylistic standards made science less accessible and less interesting for students; and he also states that teachers are likely to leave a great deal of the semantics and syntax of scientific language entirely implicit.

Teachers, according to both Lemke (1990) and Gibbons (2003), should interact directly with students regarding scientific discourse, explain linguistic relations within scientific concepts, and offer students more practise in discussion about science. They advocate teaching English language the essential technical words, syntactic phrases, and speech modes by first utilising informal or daily speech to ensure that pupils understand the information and concepts being educated.

Hiebert (2008) provides a comprehensive overview of the difficulties and benefits of learning science jargon. It's not easy to avoid science terminology. When you come across an unfamiliar word in a science literature, it is almost always crucial to the meaning of the sentence and, in some cases, the whole section. In contrast to other genres of writing, such as fiction, skipping over and reading on is unlikely to aid comprehension. Science, along with many other subject areas, employs a large variety of broader academic terms.

As per Scott (1992), "Language plays roles in science learning . . . science can be used to develop children's language, and . . increased knowledge of language goes hand in hand with the development of scientific ideas". Recent research studies reveal that students gain knowledge of science more effectively when they participate in literacy-related tasks. Consequently in the classroom, science and language become intertwined.

\section{Language Teaching and Scientific Research}

Language teaching is a multidimensional concept that can be defined in a variety of ways. In due course, language teaching research comprises a thorough examination of some instructional artefact or technique. This can be done expressively, in which situation it just notes what goes when the material or process is used, or it can be done analytically, in which it looks into the relationship between what is instructed and what is acquired.

Language teaching research can concentrate on instruction in a variety of circumstances and languages. It also aims to distinguish between research focused on teaching and research focused solely on learning. Consequently, this divergence is not always evident. The study focuses on the learning that occurs when students do an instructional assignment; it depends on whether the task is considered teaching.

When writing scientific articles, it is critical to utilise appropriate language; and scientists have to use apt language to communicate their results or knowledge. English has been used to produce scientific papers that discuss tense choice, clarity, preciseness, style, assortment of sentence, diction, and other features of language utilised in scientific writing.

The language of science or research papers varies from that of works of literature like stories or plays, which use figurative, ambiguous, or poetic language to entice readers; however, such language is forbidden in scientific articles. The language used in scientific research papers ought to be formal, simple, concise, and succinct language.

As per Day (1979), "In scientific writing, language need not be difficult; and the best English is that which gives the senses in the fewest short words. Literary tricks, metaphors and the like, divert attention from the message to the style. They should be used rarely, if at all, in scientific writing".

Normally in the scientific research writing the use of tenses should be simple present, simple past, and perfective aspects which are the most popular tenses employed by scientists or researchers. In scientific writing, progressive elements are infrequently employed. In case, the writer wants to provide a recommendation or deliver an instruction, he or she will use modality. The usage of tenses in non- 


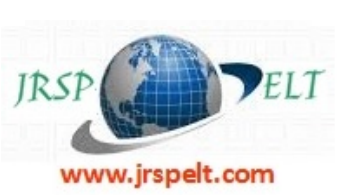

\section{Journal for Research Gébolars and 羽rofessionals of Énglish Yanguage Teaching}

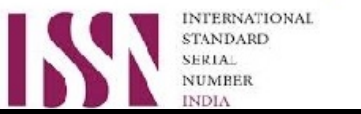

ISSN: 2456-8104

Vol. 6 | Issue 29 | January 2022

Impact Factor: 5.55 (SJIF)

www.jrspelt.com

scientific English is directed by the sense of time, while it is administered not only by time but also by non-temporal elements in technical writing.

It is supposed to write a good quality of scientific manuscript, mastering specific grammatical principles, such as the usage of tenses, is insufficient to produce a competent research article, because writing requires a variety of other abilities. In scientific/research writing, thoughts are arranged into sections and paragraphs, simultaneously appropriate words, phrases and grammatical structures have to be preferred. A direct, simple, and uncomplicated choice of language and frameworks, intended to communicate the theme with simplicity and clarity, is the finest style for writing on scientific matters. A research article is not the place for intriguing and passionate language or leisurely lyrical metaphors.

\section{Conclusion}

In this way, academic language is the language required by students to appreciate and communicate in the academic setting; and it includes specialized vocabulary, conventional text structures as well as both productive and receptive modalities. Academic language follows a set of principles that are precise, formal, and scientific, as well as objective and analytical in nature.

Academic language has been at the focus of many educational activities and academics have conceptualized academic language in a variety of ways. English has been used to produce scientific papers that discuss tense choice, clarity, preciseness, style, assortment of sentence, diction, and other features of language utilised in scientific writing; therefore, all these features of academic language are used in Scientific Research.

\section{References}

Chamot, A. U., \& O'Malley, J. M. (1994). The CALLA handbook: Implementing the cognitive academic language learning approach. White Plains, MA: Addison Wesley Longman.

Day, R. A. 1979. How to Write and Publish a Scientific Paper. Philadelphia: ISI Press.

Flynt, E., \& Brozo, W.G. (2008, March). Developing Academic Language: Got Words?. The Reading Teacher, 61(6), 500-502.

Gee, J (2004). Situated Language and Learning A Critique of Traditional Schooling. Routledge, Taylor \& Francis Group.

Gee, J 2008. What is academic language? Teaching science to English language learners: building on students' strengths, ed. by A. Rosebery and B. Warren, 57-70. Arlington VA: National Science Teachers Association Press.

Gibbons, J (2003). Forensic Linguistics: An Introduction to Language in the Justice System

Language in Society; Publisher: Wiley, 2003

Gibbons, P(2003). Mediating language learning: teacher interactions with ESL students in a content-based classroom.

TESOL Quarterly 37(2). 247-73.

Gibbons, P(2009). English learners academic literacy and thinking: learning in the challenge zone. Portsmouth, NH: Heinemann.

Godman, A. 1976. The Language of Science from the View Point of the Writer of Science Textbooks in Teaching English for Science and Technology. Anthology Series No. 2 Singapore University Press Pte. Ltd. for SEAMEO Regional Language Centre. Jack Richards (ed.) 1976. 


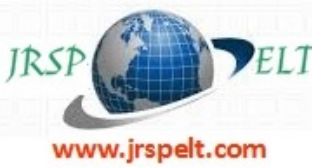

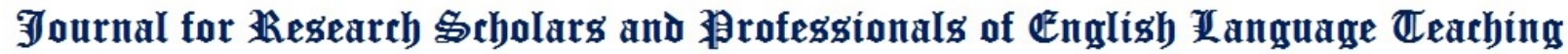

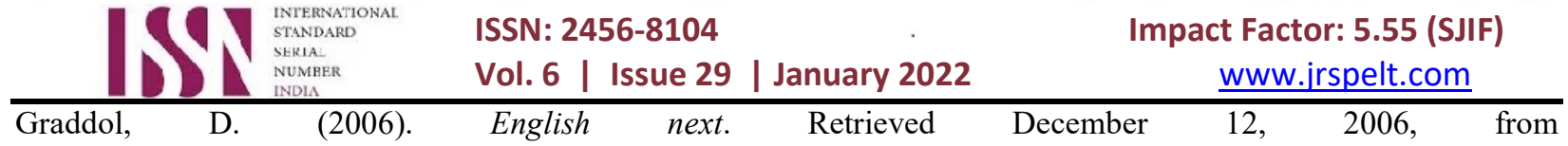

www.britishcouncil.org/files/documents/learning-research-english-next.pdf

Hiebert, E.H (2007). A core academic word list for the middle grades. Presentation at the Research Institute of the California Reading Association, Ontario, CA.

Hiebert, E. \& Lubliner, S (2008). The Nature, Learning, and Instruction of General Academic Vocabulary. In A. Farstrup \& J. Samuels (Eds.) What research has to say about vocabulary instruction. Newark, DE: International Reading Association.

Jordan, J. J. 1987. English for Academic Writing. Oxford: Oxford University Press.

Kirkman, A. J. 1980. Good Style for Scientific and Engineering Writing. London: Pitman

Publishing Limited.

Lemke, J. L. (1990). Talking Science: Language, Learning and Values. Norwood, NJ: Ablex.

Ranney, Susan (2012). Defining and Teaching Academic Language:Developments in K-12 ESL. Language and Linguistics Compass6/9 (2012): 560-574, 10.1002/lnc3.354.

Rao, C S (2018). The Use of English Language in Research. ISSN: 2456-8104 http://www.jrspelt.com Issue 8, Vol. 2, 2018.

Zwiers, J ( 2007). Teacher practices and perspectives for developing academic language. International Journal of Applied Linguistics 17(1). 93-116.

Zwiers, J (2008). Building academic language: essential practices for content classrooms. San Francisco: JosseyBass.

\section{Websites Consulted}

https://www.education.vic.gov.au/school/teachers/teachingresources/discipline/science/continuum/Pages/scilang.asp $\underline{x}$

https://www.researchgate.net/publication/264341662_Defining_and Teaching_Academic_Language_Developments in K-12_ESL

https://www.education.vic.gov.au/school/teachers/teachingresources/discipline/science/continuum/Pages/scilang.asp $\underline{x}$

https://ncte.org/statement/researchandteaching/

https://arbs.nzcer.org.nz/language-science-specialised-language

https://www.theatlantic.com/science/archive/2015/08/english-universal-language-science-research/400919/ 